\section{Medical education activities of the Association of American Medical Colleges}

Sir-The computerised application process, the Electronic Residency Application Service (ERAS) owned by the Association of American Medical Colleges (AAMC), dominates postgraduate medical education in the USA. ${ }^{1}$ Recently, medical students on my service have told me that the AAMC has additional lucrative activities. One disclosed that his wife had paid the AAMC more than $\$ 1000$ in application fees in an effort to gain admission to medical school. He also lamented that the student loan programme sponsored by the AAMC (MEDLOANS) made it difficult for him to refinance his own educational debt.

The AAMC website shows that the AAMS owns the American Medical College Application Service (AMCAS), a non-profit, centralised applicationprocessing service to the first-year entering class at participating medical schools. ${ }^{2}$ AMCAS charges each of more than 30000 medical school applicants $\$ 150$ for an initial preliminary medical school application and $\$ 30$ for each additional preliminary one., ${ }^{2,3}$ Hence, someone who applies to a fairly large number of schools will have to pay the AAMC a substantial fee, in addition to the actual medical school application fee of up to $\$ 100$ per institution paid directly to the medical school after the preliminary application. ${ }^{4}$ In the academic year 2001-02, 34859 applicants submitted 403609 applications for a total first year medical school enrolment of $16933 .^{3}$ Thus, for this group the AAMC probably received about $\$ 468$ from each of the overwhelming majority of applicants, or roughly $\$ 15$ million. Previously, there was no AAMC application fee, since applicants dealt directly with each medical school.

The AAMC seems to control and profit from the application procedures for admission to medical school and postgraduate study. ${ }^{1}$ The AAMC may possibly also benefit from medical student loans, faculty appointments, and faculty compensation through its joint venture with Computer Sciences Corporation. ${ }^{5}$ Is this expanding network of medical education undertakings appropriate? The AAMC exerts almost monopolistic domination and achieves substantial monetary gain at the expense of medical school applicants as well as medical students and immigrant physicians seeking postgraduate training. The AAMC, which I had regarded as a benign, altruistic group, has been pursuing activities that merit open discussion and careful scrutiny.

Robert A Schwartz

Dermatology, New Jersey Medical School, Newark, NJ, USA

(e-mail: roschwar@umdnj.edu)

1 Schwartz RA. Computerised application process for medical postgraduate study. Lancet 2001; 358: 589.

2 Association of American Medical Colleges. The American Medical College Application Service. http://www.aamc.org/students/ amcas/start.htm (accessed March 4, 2002).

3 Barzansky B, Etzel SI. Educational programs in US medical schools, 2001-2002. fAMA 2002; 288: 1067-72.

4 Moller MT. Medical School Admissions Requirements United States and Canada, 2003-2004. Washington: Association of American Medical Colleges, 2002.

5 AAMC News Room. Press Releases: CSC and AAMC form alliance to jointly promote mission-based management. http://www. aamc.org/newsroom/pressrel/cscaamc.htm (accessed March 4, 2002).

\section{Colour neglect in an artist}

Sir-Drawing ability could be disrupted by many neurological disorders, of which graphic neglect after unilateral brain damage (generally of right parietal cortex) is most frequent. In this disorder, patients draw preferentially on the right side of the paper, omit and deform objects on the left side, but judge their drawings to be complete. Graphic neglect can become especially evident in the work of professional painters, offering the unique opportunity to examine the effect of brain damage upon artistic graphical expression. ${ }^{1-3}$

Here, we describe a 71-year-old, right-handed, female professional painter, who had a haemorrhage in the right posterior parietal lobe, leading to left lower quadrantanopia without sensory or motor loss. Drawing and copying during neuropsychological assessment showed mild left-sided graphic neglect, but this disorder was more obvious in a spontaneous drawing (figure): the bouquet of roses is shifted to the right of the paper and is less elaborated on the left side. Left roses are distorted and deformed, whereas roses are delicately drawn on the right.

Visual inspection of her drawing showed that graphic neglect for colour (GNC) was much stronger than graphic neglect for contour or form (GNF). Use of the colours violet, orange, and green concentrates on the right side of her drawings. Whereas on the right side colour is applied completely and evenly to the drawn objects' borders, this is not the case on the left.

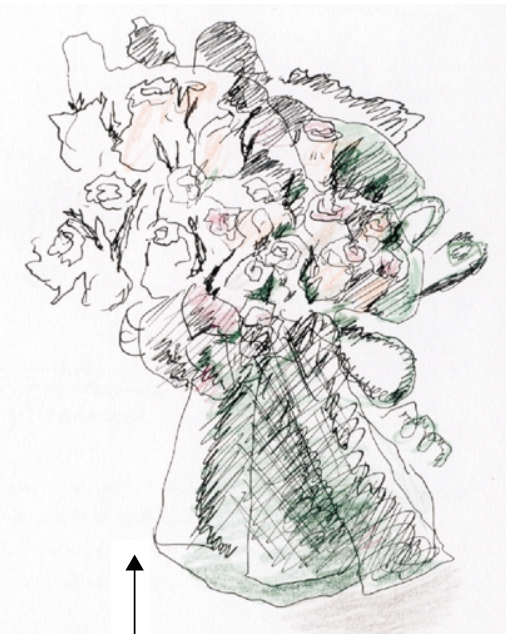

Drawing showing left colour neglect Arrow indicates the middle of the page.

GNC was stronger than GNF in 16 of 22 of the artist's coloured drawings. The difference between GNC and GNF was significant only in the left visual field (Student's $t$ test, $\mathrm{p}<0.0002)$. Neither GNC nor GNF were present in premorbid drawings and disappeared 6 weeks after brain damage.

Our findings show that parietal damage modifies an artists' drawing capacity not only in spatial terms $\mathrm{s}^{1,2}$ but also in a predominant way for a visual stimulus attribute such as colour. This finding stresses that the organisation of the cerebral cortex affects not only systematically such elementary functions as vision and manual skill but also more complex forms of human endeavour, such as artistic graphical expression. Whereas the value of psychology for art theory is widely accepted, ${ }^{4}$ our present finding suggests that neurology and neurophysiology might also offer an avenue to the artists' mind. ${ }^{1,2,5}$

* Olaf Blanke, Stéphanie Ortigue, Theodor Landis

*Department of Neurology, and Functional Brain Mapping Laboratory, Geneva University Hospital, 24 Rue Micheli-du-Crest, 1211 Geneva, Switzerland

(e-mail: olaf.blanke@hcuge.ch)

1 Halligan PW, Marshall JC. The art of visual neglect. Lancet 1997; 350: 139-40.

2 Jung R. Neuropsychologie und Neurophysiologie des Kontur und Formensehens in Zeichnerei und Malerei. In: Wieck HH, ed. Psychopathologie musischer Gestaltungen. Stuttgart: FK Schattauer, 1974: 27-88.

3 Schnider A, Regard M, Benson F, Landis T. Effects of a right-hemispheric stroke on an artist's performance. Neuropsychiatr Neuropsy Behav Neurol 1993; 6: 249-55.

4 Gombrich EH. Art and illusion. New York: Princeton University Press, 2000.

5 Zeki S. Artistic creativity and the brain. Science 2001; 293: 51-52. 